\title{
New reinforcement structures of reinforced concrete floor slabs and their technical and economic efficiency
}

\author{
Pavel Serbinovskiy ${ }^{1}$, Dmitry Mailyan $^{1, *}$, and Andrey Serbinovskiy ${ }^{1}$ \\ ${ }^{1}$ Don State Technical University, Rostov-on-Don, Russia
}

\begin{abstract}
The article deals with the new reinforcement structures of reinforced hollow core slabs, their advantages and disadvantages. Thearticle analyses their technical and economic efficiency.

Along with the new construction, the reconstruction and the total renovation of existing buildings are being actively carried out. The given works are produced both for defectselimination of building structures, and for buildings re-profiling, which causes loads increase on the floors. Therefore, issues related to the reinforcement of building structures are getting more and more urgent [1-4]. Here, it is worth paying special attention to the prefabricated reinforced concrete structures.

Several types of reinforcement structures for these slabs have been developed and patented [5-15]. Based on these patents, four (4) basic types of reinforcement structures were developed. In the first type, the reinforcement bar is located below the hollowness of the slab. In the second type, the reinforcement bar is located in a slot punched between the bottom of the hollowness and the bed of the slab. In the third type, the reinforcement bar is located under the bed of the slab. In the fourth type, the reinforcement bar is located at a certain distance from the bed of the slab in a monolithic rib, connected with the hollowness of the slab. The technical characteristics of reinforcement were checked and confirmed experimentally on full-scale samples. For the experiment, five series of slabs PC-42.12-6T were manufactured on the basis of the working drawings of the series 1.141-1 at.60, one series for each type of reinforcement and one for testing without reinforcement.
\end{abstract}

\section{Introduction}

The reinforcement structure is a reinforcement bar set below the hollownessof the slab [56]. The anchorage of the reinforcement bar is carried out with the help of end anchor attached to the bar which are embedded in concrete keys located in the hollowness and holes of the top and bottom flanges of the slab. In this case, the reinforcement cages are placed in the keys on both sides of thebar. The installation of the reinforcement bar, reinforcement cages and concrete casting of the keys is performed through the holes punched on the top and bottom flanges of the slab. Furthermore, an additional key was

* Corresponding author: author@email.org 
made in the central part of the slab in the hollowness. The reinforcement bar is embedded only in the central and end keys.

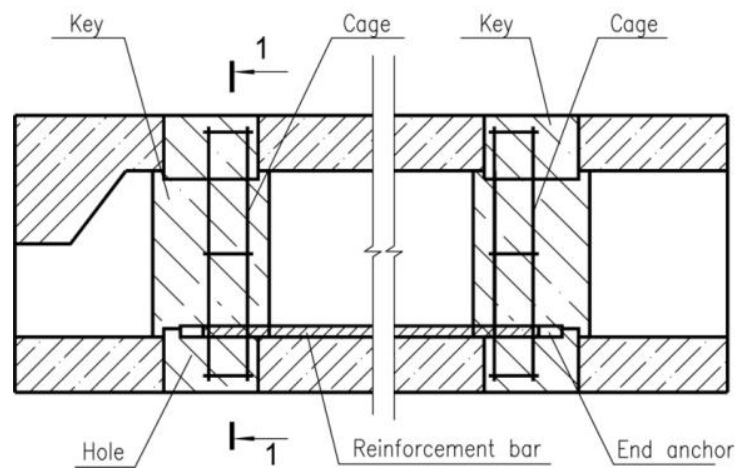

$$
1-1
$$

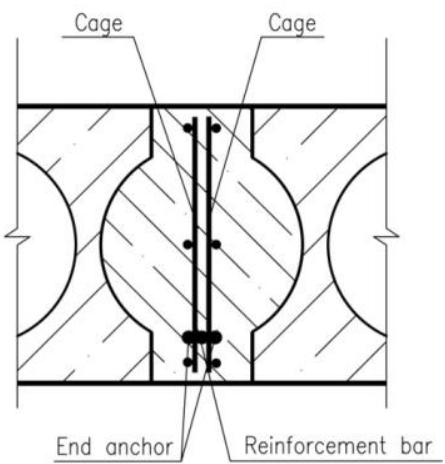

Fig. 1. Reinforcement structure of the slab IC1.

The strengthening bar is a reinforcement bar ø12 A800 with a length of $3300 \mathrm{~mm}$, the end anchors $ø 12$ A 800 with a length of $50 \mathrm{~mm}$ are welded to it. This structure was installed in the design position through the holes made on the top flange. Then, with the help of a binding wire, four cages consisting of two longitudinal bars ø4 B500 with a length of 210 $\mathrm{mm}$ located at a distance of $70 \mathrm{~mm}$ from each other and connected by three transverse bars $ø 4$ B500 with a length of $100 \mathrm{~mm}$ in steps of $90 \mathrm{~mm}$ were fastened to it. The cages were installed so that their longitudinal bars were located at the end anchors, and their upper and lower parts were embedded on the top and bottom flanges. Concrete casting of the keys was made with concrete B30.

\section{The reinforcement structure IC2}

The reinforcement structure is a reinforcement bar set at the level of the existing reinforcement in the slot punched on the bottom flange of the slab under the hollowness of the slab [7-12]. Anchorage of this bar is carried out with the help of end anchors, embedded in the keys. The keys were made at the punching holes. The holes were punched at the end of the slots. In this case, the beds of the holes adjacent to the slot were made at an angle of 450 to the axis of the bar. Furthermore, in the central part of the slab, an additional key was made. The reinforcement bar is embedded only in the central and end keys.
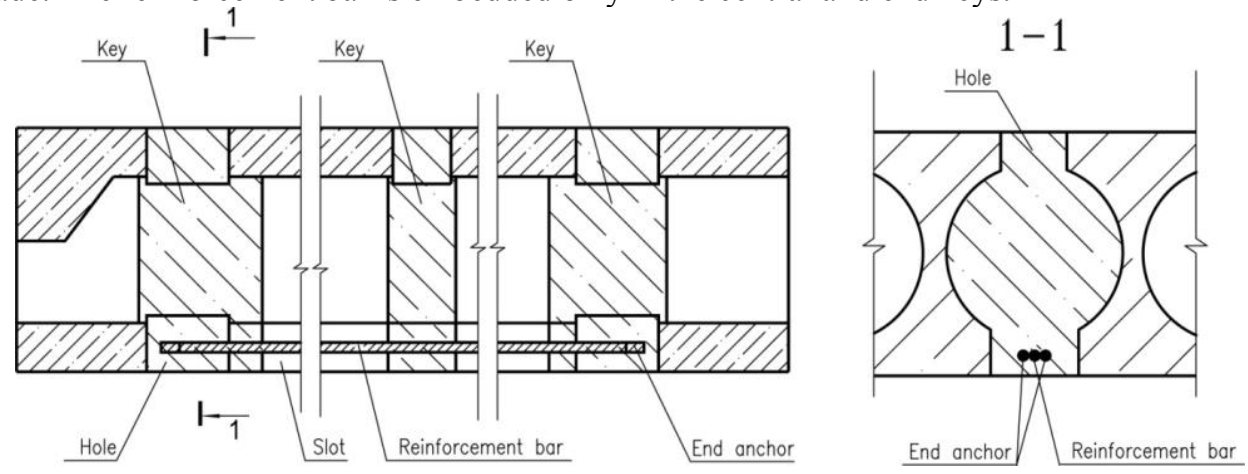




Fig. 2. Reinforcement structure of the slabIC2.

The strengthening bar is a reinforcement bar ø12 A800 with a length of $3300 \mathrm{~mm}$. The end anchors $ø 12$ A800 with a length of $50 \mathrm{~mm}$ are welded to it. Concrete casting for the keys was made with concrete B30.

\section{The reinforcement structure IC3}

The reinforcement structure is a reinforcement bar with bent ends located below the bed of the slab [13]. The bent ends of the bar pass through the holes on the top and bottom flanges of the slab and are embedded into the keys. In the places of the bend, the supports made of sheet metal were welded to the bar. The bar is equipped with end anchors. In the central part of the slab, a key was embedded. At the reinforcement bar, only the bends are embedded.
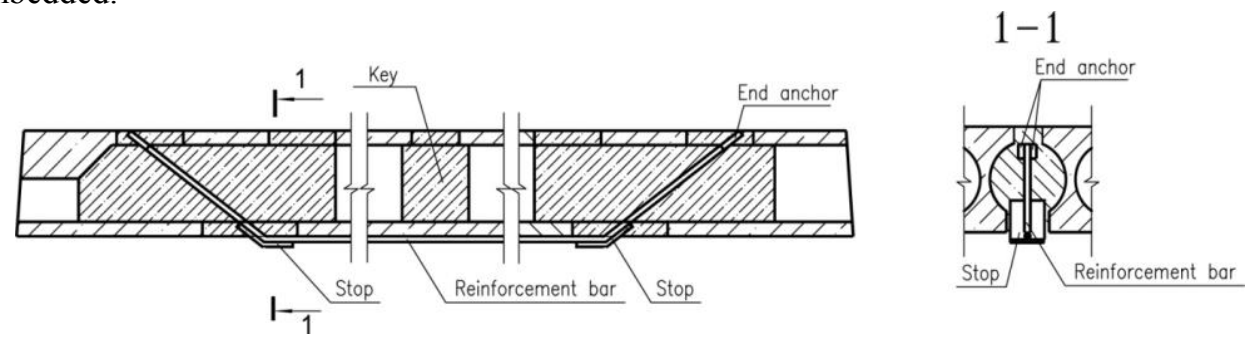

Fig. 3. Reinforcement structure of the slabIC3.

The strengthening bar is a reinforcement bar $ø 12$ A800 with a length of $3860 \mathrm{~mm}$. The end anchors $ø 12$ A800 with a length of $50 \mathrm{~mm}$ are welded to it. Concrete casting for the keys was made with concrete B30. The supports are made of sheet metal and have the size $60 \times 60 \times 5 \mathrm{~mm}$. Concrete casting for the keys was made with concrete B30.

\section{The reinforcement structure IC4}

The reinforcement structure is a reinforcement cage embedded in the hollowness of the slab, on the bottom flange of the slab and in the newly made rib located below the bed of the slab[14-15]. 



Fig. 4. Reinforcement structure of the slabIC4.

The cage consists of a lower longitudinal bar ø12 A800 with a length of $3865 \mathrm{~mm}$ with bent ends and an upper longitudinal bar ø4 B500 with a length of $3525 \mathrm{~mm}$, located 225 $\mathrm{mm}$ from each other. The longitudinal bars are connected with fifteen transverse bars $ø 4$ B500 with a length of $250 \mathrm{~mm}$, installed with a pitch of $200 \mathrm{~mm}$.

To install the cage on thebottom flange of the slab between the hollowness and the bottom bed of the slab, a slot with a length of $3400 \mathrm{~mm}$ and a width of $60 \mathrm{~mm}$ was punched. The cage was installed in the hollowness through the punched slot. The distance from the bed of the slab to the center of the cross-section of the lower longitudinal bar was $72 \mathrm{~mm}$. Concrete casting for the rib at the bed of the slab the formwork is set. Concrete casting was carried out through the holes on the top flange of the slab with concrete B30. The rib is sized in $80 \times 80 \mathrm{~mm}$.

\section{Analysis of technical and economic efficiency of reinforcement structures}

To perform the economic analysis of reinforcement structures effectiveness, the labour intensity and the cost of each reinforcement type are determined on the basis of the current normative documents. These data are given in Tables 1-4.

Table 1. Labour intensity and cost of reinforcement IC1.

\begin{tabular}{|c|c|c|c|c|c|}
\hline & $\begin{array}{c}\text { Holepunching, } \\
\text { pieces }\end{array}$ & $\begin{array}{c}\text { Slot } \\
\text { punching, } \\
\mathrm{m}\end{array}$ & $\begin{array}{c}\text { Reinforcement } \\
\text { installation, } \\
\mathrm{t}\end{array}$ & $\begin{array}{c}\text { Preparation } \\
\text { ofconcrete, } \\
\mathrm{m}^{3}\end{array}$ & $\begin{array}{c}\text { Concrete } \\
\text { casting, } \\
\mathrm{m}^{3}\end{array}$ \\
\hline Volume & 4 & - & 0,0030 & 0,011 & 0,011 \\
\hline $\begin{array}{c}\text { Labourcosts, } \\
\text { person-hour. }\end{array}$ & 1,7 & - & 0,082 & 0,03 & 0,3 \\
\hline
\end{tabular}

Total: Labour costs - 2,11person-hour.

Cost: 280,5 roubles (worker's wages)+34,1roubles (concrete)+126,3 roubles $($ reinforcement $)=440,9$ roubles.

Table 2. Labour intensity and cost of reinforcement IC2.

\begin{tabular}{|c|c|c|c|c|c|}
\hline & $\begin{array}{c}\text { Holepunching, } \\
\text { pieces }\end{array}$ & $\begin{array}{c}\text { Slot } \\
\text { punching, } \\
\mathrm{m}\end{array}$ & $\begin{array}{c}\text { Reinforcement } \\
\text { installation, } \\
\mathrm{t}\end{array}$ & $\begin{array}{c}\text { Preparation } \\
\text { ofconcrete, } \\
\mathrm{m}^{3}\end{array}$ & $\begin{array}{c}\text { Concrete } \\
\text { casting, } \\
\mathrm{m}^{3}\end{array}$ \\
\hline Volume & 5 & 3 & 0,0029 & 0,017 & 0,017 \\
\hline $\begin{array}{c}\text { Labourcosts, } \\
\text { person-hour. }\end{array}$ & 2,12 & 1,39 & 0,08 & 0,051 & 0,46 \\
\hline
\end{tabular}

Total: Labour costs - 4,1person-hour.

Cost: 545 roubles (worker's wages) $+52,7$ roubles (concrete) $+122,1$ roubles $($ reinforcement $)=719,8$ roubles. 
Table 3. Labour intensity and cost of reinforcement IC3.

\begin{tabular}{|c|c|c|c|c|c|}
\hline & $\begin{array}{c}\text { Holepunching, } \\
\text { pieces }\end{array}$ & $\begin{array}{c}\text { Slot } \\
\text { punching, } \\
\mathrm{m}\end{array}$ & $\begin{array}{c}\text { Reinforcement } \\
\text { installation, } \\
\mathrm{t}\end{array}$ & $\begin{array}{c}\text { Preparation } \\
\text { ofconcrete, } \\
\mathrm{m}^{3}\end{array}$ & $\begin{array}{c}\text { Concrete } \\
\text { casting, } \\
\mathrm{m}^{3}\end{array}$ \\
\hline Volume & 6 & - & 0,0034 & 0,022 & 0,022 \\
\hline $\begin{array}{c}\text { Labourcosts, } \\
\text { person-hour. }\end{array}$ & 2,54 & - & 0,094 & 0,066 & 0,6 \\
\hline
\end{tabular}

Total: Labour costs - 3,3person-hour.

Cost: 438,7 roubles (worker's wages) $+68,2$ roubles (concrete) $+142,8$ roubles (reinforcement $)=649,72$ roubles.

Table 4. Labour intensity and cost of reinforcement IC4.

\begin{tabular}{|c|c|c|c|c|c|}
\hline & $\begin{array}{c}\text { Holepunching, } \\
\text { pieces }\end{array}$ & $\begin{array}{c}\text { Slot } \\
\text { punching, } \\
\mathrm{m}\end{array}$ & $\begin{array}{c}\text { Reinforcement } \\
\text { installation, } \\
\mathrm{t}\end{array}$ & $\begin{array}{c}\text { Preparation } \\
\text { ofconcrete, } \\
\mathrm{m}^{3}\end{array}$ & $\begin{array}{c}\text { Concrete } \\
\text { casting, } \\
\mathrm{m}^{3}\end{array}$ \\
\hline Volume & 2 & 3,4 & 0,0044 & 0,086 & 0,086 \\
\hline $\begin{array}{c}\text { Labourcosts, } \\
\text { person-hour. }\end{array}$ & 0,85 & 1,57 & 0,121 & 0,26 & 2,34 \\
\hline
\end{tabular}

Total: Labour costs - 5,14person-hour.

Cost: 682,9roubles (worker's wages)+266,6roubles (concrete)+184.8roubles $($ reinforcement $)=1134,3$ roubles.

The cost and labor intensity of the structure IC1 are the smallest - 440.9 roubles and 2.11 person-hour. The structure IC1 does not imply the presence of its elements on the bed of the slab. The use of IC1 does not require the installation of a false ceiling.

The cost and labor intensity of thestructure IC2 are 719,8roubles and 4,1 person-hour. In comparison with IC1the following increase is caused by slot punching under the hollowness of the slab. The use of IC2 does not require the installation of a false ceiling. The IC2 structure can be performed without the access to the slab from above.

The cost and labor intensity of the structure IC3 are 649,7roubles and 3,3 person-hour. In comparison with IC2 the following decrease is caused by theabsence of slot punching. In comparison with IC1 the increase is caused by a large amount of concrete works. The IC3 structure has elements extending beyond the bed of the slab. Because of this, it becomes necessary to disassemble the structures (includingpartitions) and the equipment on the site of the reinforcement structure. The use of IC3 requires the installation of a false ceiling or the execution of a layer of plaster with a thickness of at least $30 \mathrm{~mm}$.

The cost and labor intensity of the structure IC4 are the largest - 1134,3roubles and 5,14 person-hour. In comparison with IC1- IC3 the increase is caused by thenecessity of slot punching under the hollowness of the slab and the manufacture of a concrete rib. The structure IC4 requires disassembling of structures (including partitions) and equipment on the site of installation of the reinforcement structure, as well as a false ceiling device, since it contains a ribprotruding beyond the bed of the slab. The IC4 structure can be performed without access to the slab from above.

Tables 5 and 6 give data on the magnitude of the load increase perceived by the slab when using a particular reinforcement structure, as well as the cost of increasing the load by one $\mathrm{kgf} \times \mathrm{m}$ for each reinforcement(IC1-IC4). In Table 5, we consider the increase of the load in the calculation for the first group of limit states. Table 6 considers the increase of the load in the calculation for the second group of limit states.

Table 5. The Value of load increase $(\Delta \mathrm{M})$, perceived by the slab with the use of reinforcement (IC1IC4). The ratio of reinforcement cost to the value of load increase (K) (strength). 


\begin{tabular}{|c|c|c|c|c|}
\hline & IC1 & IC2 & IC3 & IC4 \\
\hline$\Delta \mathrm{M}, \mathrm{kgf} \times \mathrm{m}$ & 1496,6 & 1622,6 & 1825,1 & 2643,8 \\
\hline $\begin{array}{c}\mathrm{K}, \\
\text { roubles } /(\mathrm{kgf} \times \mathrm{m})\end{array}$ & 0,29 & 0,44 & 0,36 & 0,43 \\
\hline
\end{tabular}

Table 6. The Value of load increase $(\Delta \mathrm{M})$, perceived by the slab with the use of reinforcement (IC1IC4). The ratio of reinforcement cost to the value of load increase (K) (rigidity and crack resistance).

\begin{tabular}{|c|c|c|c|c|}
\hline & IC1 & IC2 & IC3 & IC4 \\
\hline$\Delta \mathrm{M}, \mathrm{kgf} \times \mathrm{m}$ & 594,0 & 0 & 984,0 & 2634,0 \\
\hline $\begin{array}{c}\mathrm{K}, \\
\text { roubles } /(\mathrm{kgf} \times \mathrm{m})\end{array}$ & 0,74 & 0 & 0,66 & 0,43 \\
\hline
\end{tabular}

According to Table 5, the most profitable type of reinforcement structure for load increase in the first group of limit states is the IC1 reinforcement. However, it should be noted that as the span increases, the difference in the cost of IC3 and IC1 will be reduced, since the length does not influence on the amount of concrete work, and in IC3 the reinforcement is used more rationally, due to the larger arm of the bending couple.

According to Table 6, the most profitable type of reinforcement structure for load increase in the second group of limit states is the IC4 reinforcement. However, it should be noted that reinforcement structures of IC3 and IC4 require the reinforcement structure to extend beyond the bed of the slab, which call for the disassembling of subjacent structures and equipment, as well as arranging the ceiling spacedevice.

\section{Conclusions}

1. The reinforcement structure IC1 is recommended for use in damaged slabs reinforcement. In order to strengthen the concrete floor slabs which are in good and working condition, when the load on them is increased, the reinforcement structure IC1 is recommended in case of impossibility of using the reinforcement structure IC4 and IC3. The reinforcement structure IC1 does not imply the presence of its elements on the bed of the slab. The use of IC1 does not require the installation of a false ceiling.

2. The reinforcement structure IC2 is recommended for use in damaged slabs reinforcement in the case of a short length of the reinforcement zone (the labour intensity of making the slot is less than the labourintensity and the cost of making the keys for the IC3) and the possibility of using the reinforcement of smaller diameter in comparison with the IC1 due to the larger arm of the bending couple moment. The reinforcement structure IC2 is recommended for use in cases where the access to the slab from above is not possible, and the use of IC4 is undesirable. The use of IC2 does not require the installation of a false ceiling.

3. The reinforcement structure IC3 is recommended for use in damaged slabs reinforcement in the situationwhen it is possible to use the reinforcement of smaller diameter in comparison with the reinforcement structure IC1 due to the larger arm of the bending couple moment and the absence of conditions that prevent its use. For good and efficient floor slabs to increase the load on them, the IC3 is recommended in case of impossibility of using the IC4. The IC3 structure has elements extending beyond the bed of the slab. Because of this, it becomes necessary to disassemblethe structures (including partitions) and the equipment on the site of the reinforcement structure. The use of IC3 requires the installation of a false ceiling or the execution of a layer of plaster with a thickness of at least $30 \mathrm{~mm}$. The IC3 structure can be used for the oblique sections reinforcement.

4. The reinforcement structure IC4 is recommended for use in good and efficient floor slabs reinforcement to increase the load on them if there are no conditions preventing its use. For damaged floor slabs reinforcement the IC4 is recommended in the situation when it is 
possible to use reinforcement of smaller diameter in comparison with the reinforcement structure IC3 due to the larger arm of the bending couple moment and the absence of conditions that prevent its use. The reinforcement structure IC4 is recommended for use in cases where the access to the slab from above is not possible. The reinforcement structure IC4 requires disassembling the structures (including partitions) and equipment on the site of installation of the reinforcement structure, as well as a false ceiling device, since it contains a rib extending beyond the bed of the slab. The IC4 structure can be used for the oblique sections reinforcement.

\section{References}

1. I.N. Karlina, V.P. Novozhenin, Don Engineering Bulletin, 4 (2) (2012)

2. William D. (Dayton, $\mathrm{OH}$ ), Method of strengthening an existing reinforced concrete member. Patent US, 5,894,003 (1999)

3. Lawrence C. (Madison, WI), Anthony J. (Madison, WI), Structural reinforcement using composite strips. Patent US, 6,811,861 (2004)

4. A.V. Serbinovsky, S.S. Pinevich, P.A. Serbinovsky, E.A. Pesotsky, Don Engineering Bulletin, 1 (2015)

5. D.R. Mailyan, P.A. Serbinovsky, A.V. Serbinovsky (DSTU), The reinforcement structure of the stretched zone of precast reinforced concrete hollow core slab. Patent RF, 171934 (2017)

6. D.R. Mailyan, P.A. Serbinovsky (DSTU), The reinforcement structure of the hollow core slab. Patent RF, 167993 (2017)

7. D.R. Mailyan, P.A. Serbinovsky, A.V. Serbinovsky (DSTU), The reinforcement structure of the reinforced concrete hollow core slab. Patent RF, 2626499 (2017)

8. D.R. Mailyan, P.A. Serbinovsky (DSTU), The reinforcement structure of the stretched zone of the hollow core slab. Patent RF, 161420 (2016)

9. D.R. Mailyan, P.A. Serbinovsky (RSUCE), The reinforcement structure of the hollow core slab. Patent RF, 153650 (2015)

10. D.R. Mailyan, P.A. Serbinovsky (RSUCE), The reinforcement structure of the reinforced concrete hollow core slab. Patent RF, 154148 (2015)

11. D.R. Mailyan, D.A. Deduh, P.A. Serbinovsky (RSUCE), The reinforcement structure of the reinforced concrete hollow core slab. Patent RF, 147226 (2014)

12. D.R. Mailyan, P.A. Serbinovsky, A.V. Serbinovsky (DSTU), The reinforcement structure of the reinforced concrete hollow core slab. Patent RF, 2610951 (2017)

13. D.R. Mailyan, P.A. Serbinovsky (DSTU), The reinforcement structure of the stretched zone of the reinforced concrete hollow core slab. Patent RF, 2590494 (2016)

14. D.R. Mailyan, P.A. Serbinovsky (DSTU), The reinforcement structure of the stretched zone of the reinforced concrete hollow core slab. Patent RF, 168410 (2017) 